\title{
我国东北某鉊一鋅矿床氧化带中鋅幥脫石的研究
}

\author{
楊敏之陶克提
}

(中国科学院地盾䂰究所)

鋅濛梲石(Sauconite) 是濛脫石族中稀見的矿物 之一，䝯陆繯在美国科罗拉多、威斯康 辛、阿肯 色 ${ }^{[1,2]}$ 和苏联中哈蓬克斯坦等地 ${ }^{[3,4,5]}$ 的鉿一鋅矿休 氧化带和䃭性岩体风化壳內发現。但 到目前为止, 我国还沟有鋅濛脫石的报导和研究。

我們在进行某鉛一鋅硬床的野外工作时,在氧化 带內采到一种未知的褐色士状矿物, 經过室內詳細 工作后, 确定为鋅濛脱石。它的发現, 不只是有助

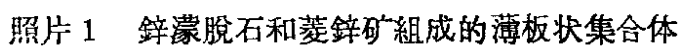
S-純鋅濛脫石（黑色）

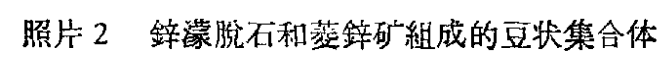

于氧化带形成和表生地球化学作用的研究, 同时也 为氧化带的分带，探寻原生鉛一鋅矿体和氧化 肭石 的綜合利用提供了重要的資料。

\section{一 鋅㴪脫石的地稹产状}

鐘濛脫石集合体成薄层状、团块状产于鉄帽带 較下部的鋅濛脫石带, 距地表 10 -15 米, 鋅濛脫石 发育在低凹地区深氧化的鉛一鋅矿体內。含鋅濛㧤 石鉛一鋅矿体氧化带的围岩是前震旦紀的白云 稹灰 岩和白云岩。原生矿体成凹鏡状沿北西一一北北西 向分标。原生矿石旷物有淡色閃鋅矿、方鉛矿、事 輪矿、黝銅矿、黃鉄矿等。該鉛一鋅矿床的成 因 类 型是低溫热液矿朱。

鋅濛脫石浅褐色一褐色，带有微弱的油脂光 泽，純的鋅濛脫石成被膜状、疏松团块状 $(0.2 \times$ 0.3 毫米一 $1.2 \times 1.0$ 毫米) 产于菱鋅矿和白鉛矿的 表面和孔隙队。少部分鋅濛脫石成菱鎊矿菱面体假 象 (1.0 0.2 毫米)，鋅濛脫石和菱鋅矿組成豆状 $(0.3 \times 0.3$ 毫米一 $0.8 \times 0.8$ 毫米, 照片 2$)$ 、薄板状 （厚0.2-1.2 毫米，照片 1) 和块状集合体。鋅濛 眖石的伡生矿物有: 菱鋅矿、白鉛矿、軟錳矿、水 釬鉄矿、褐鉄矿等。

\section{二 鋅濛脫石的物理性盾}

在电子显微鏡*下覌查鋅濛脫石成延长的鳞

* 純的鋅蒙脱石悬浮 24 小时制成悬浮液加入 $4 \%$ 的 偏橉酸鈎 ( 数小滴), 将悬浮液滴在塑料藻膜上, 烘干, 然后做透視,放大倍数 12,000 倍。由王嚜仙 同志作。 
版边緣糢糊，表面光滑。

用单变法測得鋅濛脫石在蕞光下的折光茶

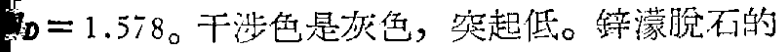
海重 2.850 (用重液法測定)。硬度 1 。在紫外光綫* 泎炤射鋅濛脫石发出天蓝色一白色的光。鋅濛脫石 的亚甲基蓝染色出現蓝色，亚甲基蓝十氯化鉀出現 色。

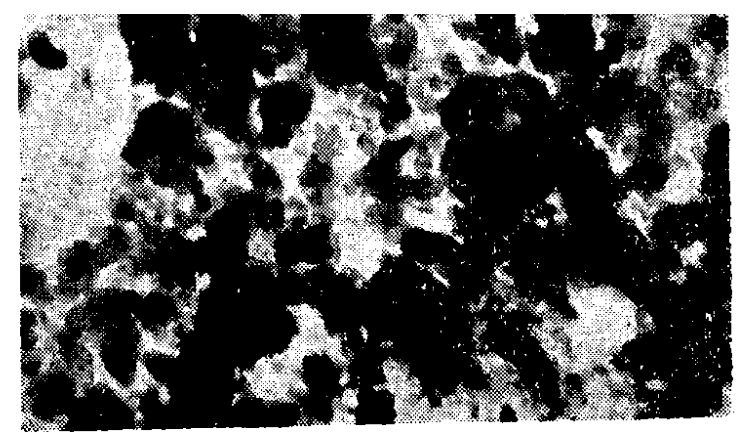

照片 3 瞵片状鎬蒙腹石电子显微鏡下照乘。 $\times 12,000$

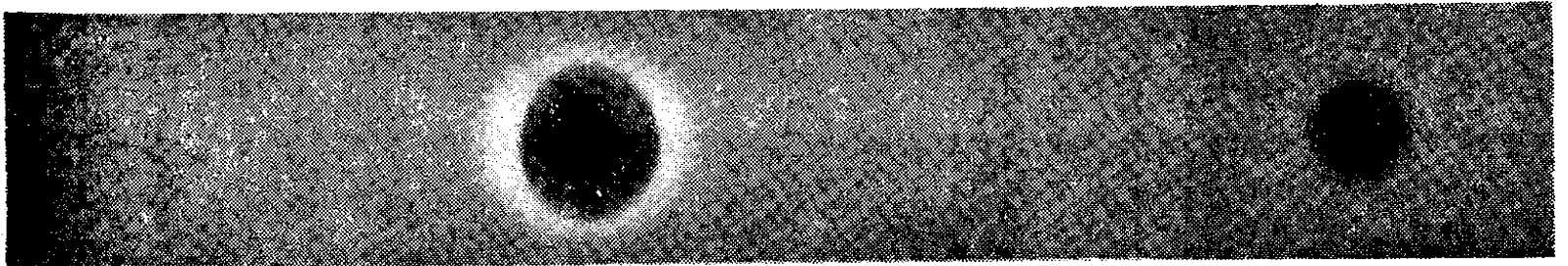

照片 4 鋅濛脱石 X-射綫粉晶分析德拜图象

\section{三鋅濛脫石的 $\mathbf{X}$-射綫分析}

选純的鋅濛脫石**經过 $\mathrm{X}-$ 射綫粉晶分析 $* * *$ 結 得表 1 , 在 X-射綫粉晶分析的德拜图上出現鋅濛 石强一一中强的特征謭綫 (照片 4)： $d_{001}=13.12$ ， $d_{p 0}=4.64, d_{130}=2.664, d_{060}=1.538$ 。这与前 对製濛脫石的 $\mathrm{X}$-射綫汾晶分析 ${ }^{[2]}$ 結果相一致。 指标化，参照前人 $\mathrm{X}$-射綫单晶分析和粉晶分 转果計算得鋅濛脫石的晶格常 数: $a_{0}=5.25 \pm$ $b_{01} \AA, b_{0}=9.26 \pm 0.02 \AA, c_{0}=13.31 \pm 0.02 \AA$, $99^{\circ} 54^{\prime} \pm 30^{\prime}, V_{0}=649.13 \AA^{3}, a_{0}: b_{0}: c_{0}=$ $566: 1: 1.43 \%$ 。

\section{四鋅脫石的热分析}

鋅濛脫石經过差热予析 ${ }^{* * * *}$,結果見图 1, 出現 五个吸热谷和二个放热峯，与前人对鋅濛脫石的 热分析 ${ }^{[2]}$ 相一致。五个吸热谷: $174^{\circ} \mathrm{C} 、 252^{\circ} \mathrm{C}$ 是 表晨間吸附水， $439^{\circ} \mathrm{C}$ 可能是二价鉄氧化的反应， $39^{\circ} \mathrm{C}$ 的吸热谷与 $\mathrm{Al}_{2} \mathrm{O}_{3}$ 的相变和部分 $[\mathrm{OH}]$ 失去有 $696^{\circ} \mathrm{C}$ 热热谷是由于晶格內 $[\mathrm{OH}]$ 的失去和相变 $\beta-\mathrm{Zn}_{2} \mathrm{SiO}_{4}$ 引起的 ${ }^{[2,6]}$ 。二个放热峯分別在 $842^{\circ} \mathrm{C}$ $955^{\circ} \mathrm{C}$, 这是与鋅濛脫石的相变(轉变为 $\alpha-\mathrm{Zn}_{2} \mathrm{SiO}_{4}$ 等) 有关。

結分果見图 2。在失重曲綫上表明鋅濛

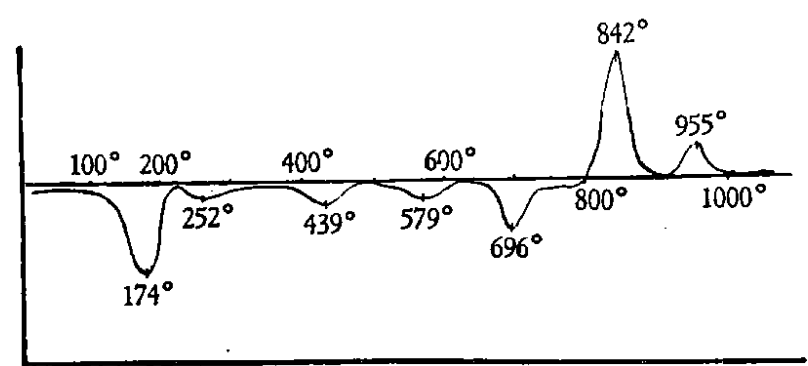

·图 1 鋅濛脫石的差热分析曲綫

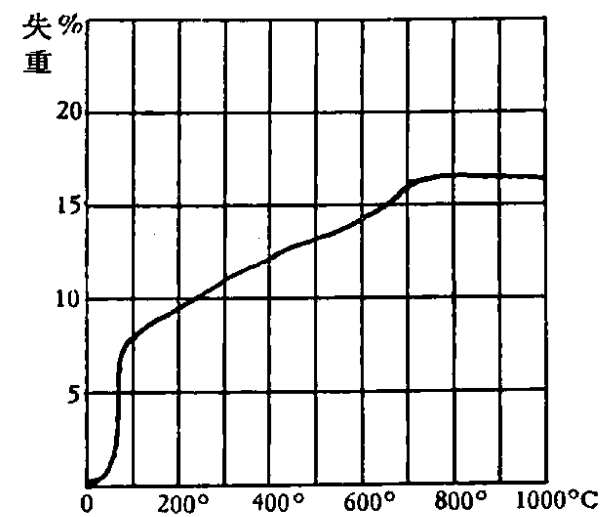

图 2 鋅膜石的脫水曲綫

* 用螢光仪测定。

** 利用手选后, 在双目鏡下检査,选出純的鋅濛脫石。

$* * *$ 月 $\mathrm{Fe}$ 耙荋射 $\left(\mathrm{Fe} \lambda_{\mathrm{k}_{\alpha}}=1.9373 \AA\right)$, 电压 $35 \mathrm{KV}$, 电流 $9 \mathrm{~mA}$, 瀑光时間 30 小时, 照象机丙径 $\varphi=114.6$ 毫 米。由任培斻同志作。

*****差热分析升溫速度草均每分鈡 $25^{\circ} \mathrm{C}$, 捡流計灵敏度 $1 \times 10^{-9}$ ，用銷一金，錦一銠热电偶。失重分析試驗时 間 90 分鈡，电压 30-120V，用自动化热重仪分析。 由吳美清同志作。 
表 1 鋅㴚脱石的 X-射綫粉晶分析絬果

\begin{tabular}{r|c|c|c||c|c|c|c}
\hline \multicolumn{2}{c|}{ 鋅 濛 } & 脱 & 石 & \multicolumn{3}{c}{ 鋅 } \\
\hline
\end{tabular}

脫石从 $16^{\circ} \mathrm{C}$ 开始脫水， $16-100^{\circ} \mathrm{C} 、 100-200^{\circ} \mathrm{C}$ 脫 去层間吸附水，200-700 ${ }^{\circ} \mathrm{C}$ 經慢脫去晶格中的 $[\mathrm{OH}]$, 到 $700^{\circ} \mathrm{C}$ 脫水結束。总的失重量 $16.0 \%$, 这与 化学分析結果 $\mathrm{H}_{2} \mathrm{O}^{+}, \mathrm{H}_{2} \mathrm{O}^{-}$的总含量 $16.68 \%$ 相近。

\section{五 鋅濛脫石的化学組成}

鋅濛脳石在盐酸、硝酸、硫酸(浓度 $1: 1$ ) 中分 解，产生絮状硅胶。鋅濛脫石加水膨胀，表現有吸 水性。

純的鋅濛脫石經化学定量全分析結果見 表 2 。 主要組分与标准鋅濛脫石相近 ${ }^{[1,2]}$ 。光謭牛定量分 析后鋅濛脫石含有微量元素: $\mathrm{Pb} \geqslant 0.1, \mathrm{Cu} 0.001$ $0.003, \mathrm{Ag}<0.0001, \mathrm{Ga} \geqslant 0.0003, \mathrm{Ca} \geqslant 0.003$, 没 有发現 $\mathrm{In} 、 \mathrm{Ge} 、 \mathrm{Ba} 、 \mathrm{Sr} 、 \mathrm{Sb} 、 \mathrm{As} 、 \mathrm{Sc}_{\text {。 }}$ 根据主要組分, 計算鋅濛脫石的結晶化学式:

$\left[\mathrm{Zn}_{1.46} \mathrm{Mg}_{0.45} \mathrm{Fe}_{0.46}^{2+} \mathrm{Al}_{0.58}\right]_{2.95}\left[\left(\mathrm{Si}_{3.38} \mathrm{Al}_{0.62}\right)_{4} \mathrm{O}_{10}\right] \times$ $\times[\mathrm{OH}]_{2} \cdot 3.99 \mathrm{H}_{2} \mathrm{O}$
表 2 鋅濛潩石的化学成分比較表

\begin{tabular}{|c|c|c|}
\hline 矿物名称 & 鋅濛胵石 & 鋅濛脱石 \\
\hline 产地 & $\begin{array}{l}\text { 中国东北某 } \\
\text { 鉛一鋅矿林 }\end{array}$ & $\begin{array}{c}\text { 美国宾多耳法 } \\
\text { 尼亚蕂抗谷 } \\
\text { (Saucon Valley) }\end{array}$ \\
\hline 成分 資料 & $1964^{\text {文 }}$ & $\begin{array}{c}\text { J. G. Fairchild } \\
1946\end{array}$ \\
\hline $\mathrm{SiO}_{2}$ & 38.68 & 34.46 \\
\hline $\mathrm{Al}_{2} \mathrm{O}_{3}$ & 11.34 & 16.95 \\
\hline $\mathrm{ZnO}$ & 22.15 & 23.10 \\
\hline $\mathrm{Fe}_{2} \mathrm{O}_{3}$ & 0.07 & 6.21 \\
\hline $\mathrm{FeO}$ & 6.27 & - \\
\hline $\mathrm{MgO}$ & 3.40 & 1.11 \\
\hline $\mathrm{CaO}$ & - & - \\
\hline $\mathrm{MnO}$ & 0.03 & - \\
\hline 'TiO & 0.52 & 0.24 \\
\hline $\mathrm{K}_{2} \mathrm{O}$ & 0.05 & 0.49 \\
\hline $\mathrm{Na}_{2} \mathrm{O}$ & 0.12 & - \\
\hline $\mathrm{H}_{2} \mathrm{O}^{+}$ & 10.45 & 6.72 \\
\hline $\mathrm{H}_{2} \mathrm{O}^{-}$ & 6.23 & 10.67 \\
\hline 总棓 & 99.31 & 99.95 \\
\hline
\end{tabular}

\section{六 鋅蒙脫石的成因及其指示意义}

1.富含鋅濛脫石的氧化带位于低山区的較低汹 地区，气候属于冷湿一溫湿区，在鉄棺带发育，氧化 程度深的鉛一鋅矿体氧化带內較富含有鋅濛脫 石。 鋅濛脫石层位于菱鋅矿带的上部，断續出現在鉃谊 带的較下部。汶都說明鋅濛脫石形成在氯化带形成 的晚期阶段。結合人工合成实驗資料 $[7,8,9]$, 說明 鋅濛脫石是在冷湿一溫湿气候, 弱碱性溶液 $(\mathrm{pH}=$ $8-9)$, 在富有 $\mathrm{ZnO} 、 \mathrm{SiO}_{2} 、 \mathrm{MgO} 、 \mathrm{Al}_{2} \mathrm{O}_{3} 、 \mathrm{H}_{2} \mathrm{O}$ 的条件 下形成。

2.鋅濛脘石成被膜状、团块状生长复盖在菱鋅 矿和白鉛矿上，被膜状軟鎾矿、褐鉄矿”复盖在鋅濛 脫石上,鋅濛脫石被軟鎑矿細脉(寬 $0.1-0.3$ 毫米) 穿文，結合結构构造特征，說明鋅濛脫石与:其伴生 矿物的生成順序如下:

$$
\text { 菱鋅矿 } \rightarrow \text { 白鉛矿 } \rightarrow \text { 鋅濛脫石 } \rightarrow \text { 潪䤾矿矿 }
$$

3.在对該矿区氧化带分带研究时，鋅濛阭石是 划分鉄帽带下限的标志，同时也是鉛一鋅研“体氧化 作用和鋅表生地球化学作用晚期阶段的重要指示 
体。鋅濛脫石的出現和分布規律的研究，能为探寻

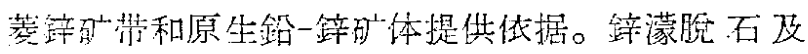
其有关共生矿物組合、綘构构造的研究能为第化矿 石的选时、治燎、綜合利用提供有利的資料。

志謝：本交蒙何作霜教授审閶，并提供意見，特此致 䶆。

[1] Ross C. S., The American Meneralogist, 31, No. 9-10, P. 411-424 (1946).

[2] Faust R. T., The American Minerulogist, 36, No. $11-12$, p. $795-822$ (1951).
[3] Гинзбург И. И., Витовская И. В., В сб.: Кора выветривания, 2 (1956).

[4] Семенов Е. И., Институт минер. геохимии и кристаллохимии редких элементов. АН СССР, Труды, 2 Стр. 124-137 (1959).

[5] Семенов Е. И., В сб.: Кора выветривания, 2, (1956).

[6] Taylor H. F. W., Amer. Mineralogist. 47, No. $7-8$, p. 932-944 (1962).

[.7] Roy D. M., Econ. Geol. 51, p. 432-443 (1956).

[8] Takahashi Tako., Econ. Geol. 55, p. 10831115 (1960).

[9] Чухров Ф. В., Қоллоиды в земной коре, ИздBO, АH CCCP, 1955.

\section{$\mathrm{NiO}-\mathrm{Li}_{2} \mathrm{O}$ 系催化剂上氧的不同吸附态*}

\section{王弘立黄桂惕 楼偑佩}

在氯化物推化剂上，氧的不同的吸附态，筸为 許多学者所假設与討諭 ${ }^{[1-4]}$ 。所有这些假設和討諭 一直缺泛实驗的竣証。最近，Казанский 等[5] 用順 磁共振法研究了在 $\mathrm{TiO}_{2}$ 上吸附氬的不同状态, 得 到了两种信号。他們䚿为这是由 $\mathrm{O}_{2}^{-}$及 $\mathrm{O}^{-}$所引起 的, 从而提供了在 $\mathrm{TiO}_{2}$ 催化济表面上存在着两种 带不同負电荷的直按实驗証据。另外，Maxim 及 Braun ${ }^{[6]}$ 在研究楅射对 $\mathrm{NiO}$ 上的化学吸附平衡的影 晌时，用不同的分析方法得到了表面氧有不同的含 量, 从而䚿为 $\mathrm{NiO}$ 上具有两种不同的化学吸附氧。 一种是弱化学吸附, 中性的; 另一种为强化学吸附, 带負电。本文应用四附过程中催化剂的逸出功和电 阻的变化, 考察了在 $\mathrm{NiO}-\mathrm{Li}_{2} \mathrm{O}$ 系催化剂上氧是否 以不同吸附态存在的問題。

共制备了近种 $\mathrm{NiO}-\mathrm{Li}_{2} \mathrm{O}$ 催化剂, 其中 $\mathrm{Li}_{2} \mathrm{O}$ 的 加入量分別相应于 $\mathrm{Li} / \mathrm{Ni}$ 原子百分比为 $0 、 0.08$ 、 0.8、4 及 $8 \%$ 。 NiO 由碳酸䤼制成，将碳酸䤼在 $600^{\circ} \mathrm{C}$ 分解三小时, 冷却至室溫, 粉碎后在 3000 大 气压下压制成片状，最后在空气中 $\left(1000^{\circ} \mathrm{C}\right)$ 活化 8 小时。 $\mathrm{NiO}-\mathrm{Li}_{2} \mathrm{O}$ 是用 $\mathrm{NiCO}_{3}$ 加入到 $\mathrm{Li}_{2} \mathrm{CO}_{3}$ 的 醋酸溶液中，㨨汼均匀后，再进行同样条件的分解 和活化制成。这五种催化剂的 BET 浸面积, 随着 $\mathrm{L}_{2} \mathrm{O}$ 加入量的坦加而減小，分別为 $0.33 、 0.33$ 、

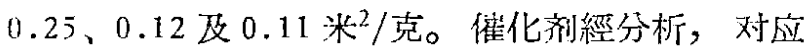
于四个含鋰催化剂, 鋰的实际含量分別为 0.04 、 $0.40 、 1.9$ 及 3.8 原子\% $\mathrm{Li}_{\text {。 }}$

催化剂經 $400^{\circ}$ 抽空 4 小时, 作为吸附前予处 理, 实驗温度为 $260^{\circ}$, 氧的初压为 $\sim 0.1$ 毫米永桂, 用 MeLeod 真空計測量压力的变化，以計算吸附量。 在測量吸附量的同时，用振动电容法測量催化剂的 逸出功, 扗在吸附进行时用交流电桥測量电阻的变 化。

* 本文曾在全国第二次催化磁究工作报告会上宣讀。 